${ }^{1}$ Faculty of Health Sciences, Universidad Autónoma de Chile, Temuco, Chile

${ }^{2}$ Faculty of Dentistry, Universidad de Concepción, Chile.

${ }^{3}$ Fundación Kimntrum, Chile
Corresponding author:

Valeria Campos

Email: valeriacamposcannobbio@ gmail.com

Editor: Dr Altair A. Del Bel Cury

Received: February 5, 2021

Accepted: March 10, 2021

\section{Factor analysis of the cross-cultural adaptation of the Multidimensional Attitudes Scale towards Deaf persons in Chilean dental students}

\author{
Valeria Campos ${ }^{1}$ iD, Luis Luengo ${ }^{2}$ iD, Ricardo \\ Cartes-Velásquez ${ }^{3, *}$ (iD
}

There are various instruments to measure attitudes toward persons with disabilities (PwD). The Multidimensional Attitudes Scale (MAS) toward PwD is a three-dimension scale with good psychometric properties; the Spanish version has been validated with a four-factor structure. Aim: To examine the factor structure of a cross-cultural adapted version of the Spanish MAS towards deaf persons in a sample of Chilean dental students. Methods: This cross-sectional study involved five Chilean public health experts that reviewed the scale for obtaining a preliminary version of a 30-item modified MAS towards deaf persons; a pilot with 15 dental students was performed, and a final sample composed of 311 students was included. For the exploratory factor analysis (EFA), maximum likelihood estimation (ML) for determining the number of factors and parallel analysis (PA) was used, with Oblimin for the rotation method. Cronbach's alpha was used to assess reliability. The root mean square error of approximation (RMSEA), comparative fit index (CFI), incremental fit index (IFI), goodness of fit index (GFI), Tucker-Lewis fit index (TLI-NNF) and root mean square of residuals (RMSR) were used to assess model fit. Results: All items had a normal distribution with the exception of items 7 and 10. The four-factor structure without item 10 in this EFA presented an adequate Cronbach's alpha $(>0.83)$, suggesting acceptable reliability. RMSEA, TLI-NNFI, RMSR, GFI and CFI indices suggested a good fit of the model and were consistent with the literature. Conclusion: The Spanish modified version of the MAS towards deaf persons has a four-factor structure, which in consistent with a previous version of the MAS.

Keywords: Deafness. Validation studies as topic. Attitude. Students, dental. Hispanic americans. Chile. 


\section{Introduction}

One out of seven persons have some kind of disability, comprising one of the most marginalized groups in the world ${ }^{1,2}$. In the case of the deaf population, more than 460 million people have a hearing disability worldwide ${ }^{2}$. In Chile, $20 \%$ of the population has a disability, from which $8.2 \%$ corresponds to a hearing disability 3 .

A significant proportion of the obstacles that people with disabilities (PwD) face when entering society are determined by the attitudes of the rest of the population, since it has been described that negative attitudes hinder their inclusion in education, employment, health care and social participation ${ }^{4-6}$. Unfavorable attitudes and feeling of discomfort regarding people with hearing disability also has been described ${ }^{7,8}$ hampering their inclusion.

Attitudes are usually defined as: "the disposition or tendency to respond positively or negatively about a certain idea, object, person or situation", which is closely related to our opinions and beliefs, and based on our own experiences ${ }^{9}$. It has been proposed that attitudes involve three components: a cognitive component that refers to thoughts, beliefs, or perceptions about an object/person; an affective component is related to emotion, which can be positive or negative; and a behavioral component linked to a way of acting ${ }^{10,11}$.

There are various instruments to measure attitudes toward PWD for general population. They can assess attitudes towards disability in general, as the Attitude to Disability Scale for people with disabilities ${ }^{12}$ or the Attitudes Towards Disabled Persons Scale $^{13}$. Also, they can assess attitudes towards a specific disability, such as Attitudes towards Deafness Scale ${ }^{14-16}$, Attitudes toward Intellectual Disability Questionnaire ${ }^{17}$ and the Multidimensional Attitudes Scale toward Persons with Disabilities (MAS) ${ }^{18}$, among others. The MAS, an originally three-dimension scale, with good psychometric properties $^{18}$, has been cross-culturally adapted to different languages reporting four dimensions ${ }^{19-22}$. Moreover, the French and Chinese modified versions of the MAS for Autism Spectrum have been validated as a four-dimension scale ${ }^{21,22}$.

Although the MAS was created to measure attitudes in the general population, the samples used in its construction and cross-cultural adaptations were mostly college students ${ }^{18-20,22}$. Moreover, as the Attitudes towards Deafness Scale was created for health professionals, there are no instruments to measure attitudes towards the deaf population in college students, including dental students. This situation could be considered a long-standing oversight in dental education research, as inclusion must be a relevant part of the training of future dentists.

Based on the above, and considering that MAS has not been used in Chile, our aim was to examine the factor structure of a cross-cultural Spanish modified version of the MAS towards deaf persons using exploratory factor analyses in a sample of Chilean dental students.

\section{Materials and Methods}

\section{Study type}

This cross-sectional study aimed to examine the factor structure of a cross-cultural Spanish modified version of the MAS towards deaf persons using exploratory factor analyses in a sample of Chilean dental students. 


\section{Sample}

The target population was comprised of dental students from Universidad de Concepción, from first to fifth year, with a grand total of 350 students. Students from sixth year were excluded as they participated in the pilot test. The final sample was composed of 311 participants; all were 18 years old or older.

There is no exact number for validation studies of scales, but between 2 to 20 participants per item are recommended, with a minimum of 100-250 participants ${ }^{22}$. The MAS scale is composed of 30 items, so the estimated sample size ranges from 60-600.

\section{Instrument}

The Spanish version of the MAS is a 30-item scale that measures attitudes towards PwD by asking participants to react to a social scenario between "José" or "Claudia" and another individual who is using a wheelchair in a public space. Thus, using a person in a wheelchair as prototypical for PwD. Respondents are asked to mark their answers on a five-point Likert scale, ranging from 1 (not at all) to 5 (very much). High scores indicate negative attitudes towards people with physical disabilities while lower scores indicate positive attitudes toward people with physical disabilities. The calm dimension items need to be inverted as they describe positive statements. In the present research, the stimulus "person in a wheelchair" was changed to "deaf person". The application of the instrument takes around 5 minutes.

The factor analysis, performed by the scale's authors, revealed the four following factors or dimensions: negative affections (11 items), calm (3 items), cognitions (10 items) and behaviors ( 6 items). The confirmatory factor analysis, conducted in all the other participants, confirmed the validity and adequacy of the model to 4 factors $(\mathrm{v} 2=2.15 ; \mathrm{RMSEA}=.068 ; \mathrm{CFI}=.88 ; \mathrm{IFI}=.88 ; \mathrm{TLI}=.87)^{19}$.

\section{Validation assessment}

Face and content validity was executed via a cross-cultural adaptation process which was carried out according to Beaton et al. ${ }^{23}$. Five Chilean public health experts with different academic backgrounds were selected for the committee, which included a psychologist with expertise in disability research and validation studies, three health researchers with experience in disability and public health, and a statistician with experience in validating instruments in health sciences. The committee reviewed the process for obtaining a preliminary version of a modified Chilean version of the MAS towards deaf persons regarding feasibility, readability, consistency of style and formatting and the clarity of the language used. A test with the pre-final version was carried out with 15 dental students in sixth year at the University of Concepción. The difficulties and problems of understanding the instrument were evaluated, and a few changes were made in the final version of the instrument regarding the clarity of the language used.

Cross-cultural adaptation: The original Spanish version says (José/Claudia) with a person in a wheelchair (female/male). Firstly, only the stimulus of "person in wheelchair" was replaced by "deaf person". As students during the pilot reported getting confused whether to focus on José or Claudia and if the deaf person was female or male, after the pilot it was decided to develop four versions of the instrument, one that 
says "José" and a "young deaf male"; "José" and a "young deaf female"; "Claudia" and a "young deaf male"; "Claudia" and a "young deaf female".

\section{Data collection}

Two researchers collected sociodemographic data and the application of the instrument through an auto applied survey. To ensure that the questions are not addressed to the respondent directly but based on a projection mechanism ensuring greater honesty of the answers, the four versions were randomly distributed to female/male participants. Data were collected in the classroom at the beginning of theory or clinical activities, during the first two months of the second semester of 2018. Each course was visited twice in case a student was absent the first time. There was no monetary nor academic compensation associated with participation. All students were invited to participate.

Each student was informed of the study aim and their voluntary participation was obtained through signed informed consent. Participants answered the modified version of the MAS towards deaf persons and provided sociodemographic data.

\section{Ethics}

This study was approved by the Research and Bioethics Committee of the Universidad de Concepción School of Dentistry (C.I.Y.B. N053/17) and was conducted in full accordance with the World Medical Association Declaration of Helsinki. All respondents agreed to voluntary participate by providing signed informed consent. The survey was anonymous, and the information was used only for the purposes of this research.

\section{Statistical analysis}

Data were tabulated in an Excel spreadsheet (MS Corp., USA). To examine the adequacy of the data, a multivariate normal distribution was executed by examining the univariate symmetry coefficient and kurtosis of each item, the Pearson correlation matrix with the Bartlett test of sphericity, and Kaiser-Meyer-Olkin (KMO).

For the exploratory Factor Analysis (EFA), Maximum likelihood estimation (ML) for determining the number of factors Parallel analysis (PA) was used with Oblimin for rotation method, loadings lower than 0.3 were not considered. Finally, to determine reliability, Cronbach's alpha was calculated for the total score and subscale scores.

The indices used to determine the model fitness were root mean square error of approximation (RMSEA), the comparative fit index (CFI), incremental fit index (IFI), Goodness of Fit Index (GFI), Tucker-Lewis fit index (TLI-NNF) and for the fitted residuals Root Mean Square of Residuals (RMSR).

Data analyses were conducted using STATA 16 (Stata Corp., USA) and FACTOR 10 (Universitat Rovira I Virgili, Spain).

\section{Results}

The sample was composed of 311 participants. Table 1 details the changes made on this adapted version from the original one. In general, all items had a normal distribution, with the exception of items 7 and 10 (Table 2). Different models were executed in order to determine the best fit. 
Table 1. Adaptations made from the original MAS.

\begin{tabular}{|c|c|}
\hline Original version: & $\begin{array}{l}\text { Imagine la siguiente situación. José/Claudia fue a almorzar con un grupo de amigos a un } \\
\text { restaurante. Una persona en silla de ruedas, a quien José/Claudia no conoce, entra en la } \\
\text { cafetería y se une al grupo. }\end{array}$ \\
\hline First version for pilot: & $\begin{array}{l}\text { Imagine la siguiente situación. José/Claudia fue a almorzar con un grupo de amigos a un } \\
\text { restaurante. Una persona sorda, a quien Mario/María no conoce, entra en el restaurante y } \\
\text { se une al grupo. }\end{array}$ \\
\hline Final versions & $\begin{array}{l}\text { 1. Imagine la siguiente situación. Claudia fue a almorzar con un grupo de amigos a un } \\
\text { restaurante. Una joven sorda, a quien Claudia no conoce, entra en el restaurante y se une al grupo } \\
\text { 2. Imagine la siguiente situación. Claudia fue a almorzar con un grupo de amigos a un } \\
\text { restaurante. Un joven sordo, a quien Claudia no conoce, entra en el restaurante y se une al grupo. } \\
\text { 3. Imagine la siguiente situación. José fue a almorzar con un grupo de amigos a un } \\
\text { restaurante. Una joven sorda, a quien José no conoce, entra en el restaurante y se une al grupo } \\
\text { 4. Imagine la siguiente situación. José fue a almorzar con un grupo de amigos a un } \\
\text { restaurante. Un joven sordo, a quien José no conoce, entra en el restaurante y se une al grupo. }\end{array}$ \\
\hline
\end{tabular}

Table 2. Symmetry measures for each item.

\begin{tabular}{|c|c|c|}
\hline Item & Asymmetry & Kurtosis \\
\hline p12 &,- 536 &,- 222 \\
\hline p13 &,- 421 &,- 412 \\
\hline p14 &,- 381 &,- 433 \\
\hline p21 &,- 201 &,- 849 \\
\hline p30 &,- 168 &,- 677 \\
\hline $\mathrm{p} 4$ &,- 164 &,- 738 \\
\hline p18 & ,073 &,- 565 \\
\hline p22 & 109 &,- 878 \\
\hline p3 & , 130 &,- 721 \\
\hline p9 & , 155 &,- 906 \\
\hline p27 & , 178 & $-1,081$ \\
\hline p1 & ,276 &,- 664 \\
\hline p15 & ,312 &,- 627 \\
\hline p19 & ,361 &,- 040 \\
\hline p17 & ,363 &,- 338 \\
\hline p16 & ,390 &,- 359 \\
\hline p20 &, 420 &,- 315 \\
\hline p29 & ,465 & $-1,025$ \\
\hline p23 & ,493 &,- 193 \\
\hline p24 & ,624 &,- 304 \\
\hline p25 & ,669 &,- 654 \\
\hline p8 & ,745 &,- 779 \\
\hline p6 & 1,033 & ,047 \\
\hline p5 & 1,108 & , 197 \\
\hline p26 & 1,162 & ,588 \\
\hline p28 & 1,391 & 1,170 \\
\hline p2 & 1,491 & 2,213 \\
\hline p11 & 1,604 & 1,662 \\
\hline p7 & 1,878 & 2,933 \\
\hline p10 & 2,730 & 7,582 \\
\hline
\end{tabular}




\section{Model 1}

All 30 items were included. A significant Bartlett test of sphericity was obtained $(p<0.001)$ and a KMO of 0.855 and an overall 0.8779 Cronbach's alpha. The $\mathrm{ML}$ and PA analysis advised a four-dimension model (Table 3a) The Oblimin rotation for the advised model (Table 4a) showed a good internal consistency (Factor $1=0.8918$; Factor 2=0.9038; Factor 3=0.8332, Factor 4=0.8315). In Table 5, indices of the fitted model can be observed. The dimensions were: negative effects (11 items), calm (3 items), cognition (10 items) and behaviors (6 items).

Table 3. Parallel Analysis with and without item 10.

\begin{tabular}{lcccccc}
\hline \multicolumn{7}{l}{ Parallel analysis based on minimum rank factor analysis } \\
\cline { 2 - 7 } Factor & $\begin{array}{c}\text { With all-30 items } \\
\text { Real-data \% of } \\
\text { variance }\end{array}$ & $\begin{array}{c}\text { Mean of } \\
\text { random \% of } \\
\text { variance }\end{array}$ & $\begin{array}{c}\text { 95 percentile } \\
\text { of random \% } \\
\text { of variance }\end{array}$ & $\begin{array}{c}\text { Real-data \% of } \\
\text { variance }\end{array}$ & $\begin{array}{c}\text { Mean of } \\
\text { random \% of } \\
\text { variance }\end{array}$ & $\begin{array}{c}\text { 95 percentile } \\
\text { of random \% } \\
\text { of variance }\end{array}$ \\
\hline 1 & $\mathbf{2 6 . 3 8 5 4 ^ { * }}$ & 69.362 & 74.966 & $\mathbf{2 5 . 2 2 9 8 ^ { * }}$ & 7.1391 & 7.6882 \\
\hline 2 & $\mathbf{1 6 . 9 5 8 2 ^ { * }}$ & 64.800 & 69.601 & $\mathbf{1 6 . 4 0 0 8 *}$ & 6.6773 & 7.1497 \\
\hline 3 & $\mathbf{9 . 7 3 7 5 ^ { * }}$ & 61.474 & 65.788 & $\mathbf{9 . 2 2 5 4 *}$ & 6.3391 & 6.7502 \\
\hline 4 & $\mathbf{6 . 6 1 7 9 *}$ & 58.574 & 62.246 & 5.7940 & 6.0279 & 6.3777 \\
\hline 5 & 48.204 & 55.969 & 59.386 & 4.6558 & 5.7579 & 6.0850 \\
\hline 6 & 40.024 & 53.474 & 56.637 & 3.9223 & 5.4936 & 5.8099 \\
\hline 7 & 30.881 & 51.249 & 54.152 & 3.4597 & 5.2535 & 5.5521 \\
\hline 8 & 30.179 & 48.883 & 51.499 & 3.2321 & 4.9963 & 5.2848 \\
\hline
\end{tabular}

Table 4. Oblimin rotated loading matrix for models 1-3.

\begin{tabular}{|c|c|c|c|c|c|c|c|c|c|c|c|}
\hline \multirow[b]{2}{*}{ Item } & \multicolumn{4}{|c|}{ Model 1} & \multicolumn{4}{|c|}{ Model 2} & \multicolumn{3}{|c|}{ Model 3} \\
\hline & F- 1 & $\mathrm{~F}-2$ & F- 3 & F-4 & F- 1 & F- 2 & F-3 & F- 4 & $\mathrm{~F}-1$ & F- 2 & F-3 \\
\hline p1 & & & 0.567 & & & & 0.587 & & & 0.456 & \\
\hline p2 & & & 0.439 & & & & 0.383 & & & 0.542 & \\
\hline p3 & & & 0.737 & & & & 0.776 & & & 0.522 & \\
\hline p4 & & & 0.766 & & & & 0.819 & & & 0.474 & 0.353 \\
\hline p5 & & & 0.594 & & & & 0.543 & & & 0.411 & \\
\hline p6 & & & 0.583 & & & & 0.583 & & & 0.372 & \\
\hline p7 & & & 0.443 & & & & 0.563 & & & 0.543 & \\
\hline p8 & & & 0.465 & & & & 0.383 & & & 0.324 & \\
\hline p9 & & & 0.544 & & & & 0.450 & & & 0.330 & 0.314 \\
\hline p10 & & & 0.438 & & & & & & & & \\
\hline p11 & & & 0.401 & & & & 0.353 & & & 0.362 & \\
\hline p12 & 0.755 & & & & & & & 0.742 & & & 0.749 \\
\hline p13 & 0.935 & & & & & & & 0.951 & & & 0.893 \\
\hline p14 & 0.894 & & & & & & & 0.888 & & & 0.879 \\
\hline p15 & & 0.577 & & & & 0.576 & & & 0.603 & & \\
\hline p16 & & 0.679 & & & & 0.680 & & & 0.700 & & \\
\hline
\end{tabular}


Continuation

\begin{tabular}{|c|c|c|c|c|c|}
\hline p17 & 0.760 & & & 0.755 & 0.782 \\
\hline p18 & 0.658 & & & 0.668 & 0.661 \\
\hline p19 & 0.798 & & & 0.790 & 0.799 \\
\hline p20 & 0.766 & & & 0.755 & 0.751 \\
\hline p21 & 0.622 & & & 0.639 & 0.590 \\
\hline p22 & 0.506 & & & 0.517 & 0.472 \\
\hline p23 & 0.748 & & & 0.749 & 0.732 \\
\hline p24 & 0.653 & & & 0.654 & 0.617 \\
\hline p25 & & 0.869 & 0.862 & & 0.760 \\
\hline p26 & & 0.834 & 0.837 & & 0.735 \\
\hline p27 & & 0.632 & 0.615 & & 0.621 \\
\hline p28 & & 0.680 & 0.702 & & 0.647 \\
\hline p29 & & 0.681 & 0.677 & & 0.704 \\
\hline p30 & & 0.346 & 0.329 & & 0.304 \\
\hline
\end{tabular}

Table 5. Comparison of indices of the adjusted models.

\begin{tabular}{lcccc}
\hline & Model 1 & Model 2 & Model 3 & Expected values \\
\hline RMSEA & 0.076 & 0.075 & 0.095 & $\leq 0.08$ \\
\hline TLI-NNFI & 0.911 & 0.916 & 0.868 & $\geq 0.85-0.90$ \\
\hline RMSR & 0.0501 & 0.0473 & 0.0656 & $\leq 0.0568$ \\
\hline GFI & 0.971 & 0.975 & 0.920 & $\geq 0.95$ \\
\hline CFI & 0.935 & 0.939 & 0.895 & $\geq 0.90$ \\
\hline
\end{tabular}

Root mean square error of approximation (RMSEA), Comparative fit index (CFI), Incremental fit index (IFI), Goodness of Fit Index (GFI), Tucker-Lewis fit index (TLI-NNF), and Root Mean Square of Residuals (RMSR).

\section{Model 2}

A second model was executed after eliminating item 10. A significant Bartlett test of sphericity was obtained $(p<0.001)$ and a KMO of 0.85483 and an overall 0.8761 Cronbach's alpha. The ML and PA analysis advised a three-dimension model (Table 3b). The Oblimin rotation for the four-dimension model (Table $4 \mathrm{~b}$ ) showed a good internal consistency (Factor 1= 0.8918; Factor 2=0.9038; Factor 3=0.8332; Factor 4=0.8315). In Table 5, indices of the fitted model can be observed. The same structure as model 1 was observed.

\section{Model 3}

As the $M L$ and PA analysis advised a three-dimension structure, we executed the Oblimin rotation for the three-dimension model without item 10 (Table 3c), which showed good internal consistency (Factor $1=0.8918$; Factor $2=0.9038$; Factor $3=0.8506$ ). However, this model presented a different structure, as the dimension negative affections was blended with the dimension behaviors.

\section{Discussion}

The four-factor structure without item 10 in this EFA presented an adequate Cronbach's alpha, suggesting acceptable internal consistency. Moreover, the RMSEA, TLI-NNFI, RMSR, 
GFI and CFI indices suggested a good fit of the model. Also, it showed the best fitted model and was consistent with the literature ${ }^{19-22}$. All items loaded in a factor with the same four-factor structure, suggesting similarities with the Colombian version of the MAS ${ }^{19}$.

When examining the pattern of item loadings, though all 30 items loaded with an exceeding absolute value of 0.3 into a factor, item 10 was removed from the scale because of cultural differences. Although the word "Depresión" is a direct translation of "Depression", in Chile, it only has the strong connotation of a diagnosed mental illness, unlike in other countries which it also has the connotation of emotions such as "sadness" or "sorrow". In the adaptation process, that item was identified as likely problematic, a situation which was confirmed in the EFA, which finally suggested its exclusion from this adapted version. In this sense, depression was not considered a consistent part of the attitudes toward deaf persons in this sample.

Criterion validation was not possible because there were no validated instruments in Chile regarding attitudes towards PwD. Moreover, as this instrument was already in Spanish, a confirmatory analysis (CFA) might have been suggested, but as the stimulus "person in a wheelchair" was changed to "deaf person", an EFA was mandatory in other to pursue further analysis.

Several limitations should be considered when interpreting the results of this study. First, the sample consisted of individuals receiving undergraduate dental education, as we were interested in determining the effect of an elective course ${ }^{24}$ on attitudes towards deaf persons. As it has been determined that higher levels of education are associated with more positive attitudes, future studies should also be conducted with different samples and with lower or higher education levels. Secondly, the MAS is an explicit instrument, so it is possible that social desirability or other factors could have influenced how participants responded. This is contrasted with what was previously reported, where the results of the Implicit Association Test (IAT) did not correlate generally with the results of explicit scales ${ }^{25,26}$. Therefore, future studies should focus on designing IATs toward people with disabilities in Chile. Third, the sample size did not allow us to divide the sample in two in order to run an EFA with one subsample and a CFA with the other, so it is recommended to consider sample sizes of 500 participants and over. Finally, although the TLI-NNFI, RMSR, GFI and CFI indices suggested a good fit of the model for the four-factor solution, the RMSEA suggested an adequate - but not good - fit.

Among the strengths of this study is that this Spanish modified version of the MAS may serve as a useful tool in identifying attitudes towards deaf persons and, from there, generate strategies to address them. Different entities such as the World Health Organization have stated the urgent need for policies that promote the inclusion of $\mathrm{PwD}^{1-2}$. However, to achieve the latter in Chile, validated instruments are needed in order to determine these current attitudes. Secondly, no student refused to participate, which strengthens our results. Another strength is the diverse background of the expert panel, supporting an adequate adaptation process.

Despite these limitations, it is important to remember that the validation process is permanent, and there is no study that can assure that any instrument has full validity, as each validation study adds evidence on different aspects of the validity for specific uses and particular populations for an individual instrument. 
In conclusion, the Spanish modified version of the MAS towards deaf persons has a four-factor structure, which in consistent with previous version of the MAS.

\section{Ethics Approval}

This study was approved by the Research and Bioethics Committee of the Universidad de Concepción School of Dentistry (C.I.Y.B. N053/17) and was conducted in full accordance with the World Medical Association Declaration of Helsinki.

\section{Consent to Participate}

Each student was informed of the study aim and their voluntary participation was obtained through signed informed consent.

\section{Conflict of Interest}

None

\section{Acknowledgements}

None

\section{References}

1. World Health Organization. Disability and Health: Fact Sheet No 352. Geneva: WHO; 2015.

2. World Health Organization. The World Bank. World report on disability. Malta: WHO; 2011.

3. Ministry of Social Development. Second National Study of Disability. Chile: Ministry of Social Development; 2015

4. Stone DL, Colella A. A model of factors affecting the treatment of disabled individuals in organizations. Acad Manag Rev. 1996 Apr;21(2):352-401.

5. Eagly $\mathrm{AH}$, Chaiken S. The advantages of an inclusive definition of attitude. Soc Cognition. 2007;25(5):582-602. doi: 10.1521/soco.2007.25.5.582

6. Patka M, Keys CB, Henry DB, McDonald KE. Attitudes of Pakistani community members and staff toward people with intellectual disability. Am J Intellect Dev Disabil. 2013 Jan;118(1):32-43. doi: 10.1352/1944-7558-118.1.32.

7. Meadow-Orlans K, Erting C. Deaf people in society. In: Hindley P, Kitson N, editors. Mental health and deafness. London: Whurr Publishers; 2000. p.3-24.

8. Ralston E, Zazove P, Gorenflo DW. Physicians' attitudes and beliefs about deaf patients. J Am Board Fam Pract. 1996;9(3):167-73.

9. Goodman B, Clemow R. Nursing and Collaborative Practice: A guide to interprofessional learning and working. 2nd ed. Exeter UK: Learning Matters; 2010.

10. Eagly AH, Chaiken S. The psychology of attitudes. Orlando: Harcourt Brace Jovanovich College Publishers; 1993.

11. Maio G, Haddock G. The psychology of attitude and attitude change. London: SAGE Publications; 2010.

12. Power MJ, Green AM, WHOQOL-DIS Group. The Attitudes to Disability Scale (ADS): development and psychometric properties. J Intellect Disabil Res. 2010 Sep;54(9):860-74. doi: 10.1111/j.1365-2788.2010.01317.x. 
13. Yuker HE, Block JR, Young JH. The measurement of attitudes toward disabled persons. Albertson, NY: Human Resources Center; 1996.

14. Cooper A, Rose J, Mason O. Measuring the attitudes of human service professionals toward deafness. Am Ann Deaf. 2004;148(5):385-9. doi: 10.1353/aad.2004.0001.

15. Belmar N, Quappe I, Luengo L, Campos V. Exploratory factor analysis of the chilean deafness attitude scale. Int J Med Surg Sci. 2018;5(2):80-8. doi: 10.32457/ijmss.2018.020.

16. Campos V, Cartes-Velásquez R, Luengo L. Chilean health professionals' attitudes towards deafness: a cross-sectional study. Pesq Bras Odontopediatria Clín Integr. 2020:20: e0020. doi: 10.1590/pboci.2020.087.

17. Morin D, Crocker G, Beaulieu-Bergeron R, Caron J. Validation of the attitudes toward intellectual disability: ATTID questionnaire. J Intellect Disabil Res. 2013 Mar;57(3):268-78. doi: 10.1111/j.1365-2788.2012.01559.x.

18. Findler L, Vilchinsky N, Werner S. The multidimensional attitudes scale toward persons with disabilities (MAS) construction and validation. Rehab Couns Bull. 2007;50(3):166-76. doi: $10.1177 / 00343552070500030401$.

19. Stevens LF, Getachew MA, Perrin PB, Rivera D, Olivera Plaza SL, Arango-Lasprilla JC. Factor analysis of the Spanish Multidimensional Attitudes Scale Toward Persons with Disabilities. Rehabil Psychol. 2013 Nov;58(4):396-404. doi: 10.1037/a0034064.

20. Radlińska I, Starkowska A, Kożybska M, Flaga-Gieruszyńska K, Karakiewicz, B. The multidimensional attitudes scale towards persons with disabilities (MAS)-a Polish adaptation (MAS-PL). Ann Agric Environ Med. 2020;27(4):613-20. doi: 10.26444/aaem/114531.

21. Dachez J, Ndobo A, Ameline A. French Validation of the Multidimensional Attitude Scale Toward Persons with Disabilities (MAS): The Case of Attitudes Toward Autism and Their Moderating Factors. J Autism Dev Disord. 2015 Aug;45(8):2508-18. doi: 10.1007/s10803-015-2417-6.

22. Lu M, Pang F, Luo J. Chinese Validation of the Multidimensional Attitude Scale toward Persons with Disabilities (MAS): Attitudes toward Autism Spectrum Disorders. J Autism Dev Disord. 2020 Oct;50(10):3777-89. doi: 10.1007/s10803-020-04435-1.

23. Beaton DE, Bombardier C, Guillemin F, Ferraz MB. Guidelines for the process of cross-cultural adaptation of self-report measures. Spine (Phila Pa 1976). 2000 Dec 15;25(24):3186-91. doi: 10.1097/00007632-200012150-00014.

24. Campos V, Cartes-Velásquez R. Developing competencies for the dental care of people with sensory disabilities: a pilot inclusive approach. Cumhuriyet Dent J. 2020;23(2):107-15. doi: 10.7126/cumudj.706518.

25. Wilson MC, Scior K. Attitudes towards individuals with disabilities as measured by the Implicit Association Test: A literature review. Res Dev Disabil. 2014 Feb;35(2):294-321. doi: 10.1016/j.ridd.2013.11.003.

26. Hein S, Grumm M, Fingerle M. Is contact with people with disabilities a guarantee for positive implicit and explicit attitudes? Eur J Spec Needs Educ. 2011;26(4):509-22. doi: 10.1080/08856257.2011.597192. 